\title{
(RE)EXISTÊNCIAS POC: MODOS DE SUBJETIVAÇÃO E ATIVISMO
}

(Re)existences POC: ways of subjectivation and activism

\author{
Cleber Sales Pereira \\ Discente de Psicologia \\ Universidade Federal do Delta do Parnaíba, Parnaíba, Brasil. \\ salllescleber@gmail.com \\ (1) https://orcid.org/0000-0003-4446-2955
}

Guilherme Augusto Souza Prado Doutor em Psicologia Clínica e Subjetividade Universidade Federal do Delta do Parnaíba, Parnaíba, Brasil. guispra@gmail.com

(1) http://orcid.org/0000-0001-9318-8580

A lista completa com informações dos autores está no final do artigo

\section{RESUMO}

O termo POC remonta à década de 1970 quando era utilizado para se referir pejorativamente aos homossexuais do sexo masculino com performance e traços afeminados. A expressão passou por um período de remissão e voltou recentemente a ser utilizada nas redes digitais de comunicação, sendo apropriada e ressignificada pela população LGBTQIA+ em um processo que a coloca em proximidade com os estudos/ativismo Transviados. O presente trabalho busca analisar o podcast POC de Cultura a partir de algumas ferramentas da abordagem foucaultiana da Análise do Discurso, entendendo o podcast como um dispositivo de auto-enunciação política no qual podemos mapear a emergência e criação de novos modos de agir, fazer, consumir, desejar e de novas verdades. Assim, nos atentamos às maneiras pelas quais a positivação do termo POC e a militância empreendida no programa resultam em efeitos éticopolíticos. Partimos da noção de corpos abjetos em uma série de processos de ressignificações e ativismo POC.

PALAVRAS-CHAVE: Ativismo LGBT. estudos QueerTransviados. Análise de Discurso. Foucault. POC.

\section{ABSTRACT}

The term POC alludes to the 1970s when it was used to refer pejoratively to effeminate performance and features of male homosexuals. The expression POC reemerged recently, been used in digital communication networks, being appropriated and reframed by the LGBTQIA+ population in a process that brings it closer to Queer studies and activism. This work aims to analyze the Podcast POC de Cultura using some tools of Foucault's Discourse Analysis, understanding the podcast as an apparatus of political self-enunciation in which we can map the emergence and creation of new ways of acting, doing, consuming, desiring and performing gender in order to invent other truths for effeminate male homosexuals. Therefore, we pay attention to the ways in which the process to positivize the term POC and the militancy conducted in the podcast results in ethical-political effects of enunciation and subjectivation. We started from the notion of abject bodies in a series of processes of reframing and POC activism.

KEYWORDS: LGBT activism. Queer/Transviados studies. Discourse Analysis. Foucault. POC.

\section{INTRODUÇÃO}

O presente trabalho versa sobre os modos de subjetivação, socialização e a cultura POC. Tomamos como problema de pesquisa a reemergência do termo POC nas redes sociais e a sua ressignificação, distinta do sentido apenas pejorativo relacionado à bicha afeminada. A expressão POC opera expandindo os domínios de representação política e 
linguística (BUTLER, 2017), na medida em que recaracteriza o que se reconhece como subjetividade POC. Com isso, emergem linguagens capazes de produzir uma positivação no entendimento do termo e, com ela, visibilidade política. É importante salientar que o termo POC passou por um período de remissão, uma vez que na década de 1970, POC $P O C$ se referia à onomatopeia do salto alto que as gays afeminadas costumavam usar. Além disso, seu emprego também esteve relacionado à abreviação da expressão bicha pão com ovo, que seria um gay afeminado e pobre (POC DE CULTURA, 2018a).

Percebendo que o termo POC era veiculado em diversos espaços, sobretudo nas redes sociais, seguimos uma pista do podcast Poc de Cultura (2018a) que indicava o uso do termo nos fóruns da rede social Pandlr e em grupos do Facebook. Por volta de 2018, usuários começaram a divulgar memes com legendas do tipo: murro na POC, em um tom pejorativo. Posteriormente, esses memes se espalharam por outras redes e começaram a ganhar novas versões menos agressivas ou positivadas como: carinho na POC.

Fazendo uma busca nos portais de divulgação científica (SciELO, Periodicos Portal da CAPES, Google Acadêmico) concluímos que a temática é pouco abordada. Por isso, escolhemos estudar os modos de subjetivação POC, em um esforço para investigar e problematizar essa categoria que subverte a coerência sexo, gênero e desejo que delimita o campo da sexualidade hegemônica e normalizada em nossa cultura. Portanto, o termo POC pode ser descrito, de maneira sucinta, como forma de existência fluidificada a partir de traços femininos e capaz de romper com a dinâmica da heterossexualidade compulsória e o sistema disjuntivo masculino/feminino, operando enquanto lugar de intervenção, denúncia e deslocamento dessas reificações (BUTLER, 2017).

Assim, o presente trabalho se caracteriza enquanto pesquisa descritiva, que busca descrever e explicar um fenômeno social e político, e de caráter exploratório, já que existem poucos estudos que abordam o tema em suas análises (LEITE, 2008). O material utilizado para a investigação são os episódios do podcast POC de Cultura e será analisado pelo viés da Análise do Discurso Foucaultina (FOUCAULT, 1999), tendo como algumas de suas ferramentas as noções de discurso, dispositivo e poder como dimensões imbricadas na produção de subjetividade. O referido programa é produzido a partir de relatos de quatro POCs que vivem em São Paulo e falam um pouco mais sobre suas vidas, dores e amores. 


\section{PODCAST POC DE CULTURA}

O termo Podcast emerge etimologicamente como "uma junção das palavras iPod com broadcast (transmissão via rádio), sendo uma forma de publicação de mídia, geralmente em áudio" (MAFORD; RAMOS; FERNANDES-SANTO, 2019, p. 2). Dessa forma, usamos os podcasts como plataforma de pesquisa, como parte das redes digitais de informação e comunicação, que ampliam os efeitos panópticos em nossa sociedade em seus diversos modos de funcionamento (BRUNO, 2013). A distribuição de tais mecanismos de controle e vigilância se dá no contexto dos movimentos participativos e colaborativos chamado de web 2.0, que designam "serviços e ambientes na Internet cujo conteúdo é produzido pelos próprios usuários" (BRUNO, 2013, p. 25). Assim, as mídias alternativas como podcasts são um espaço fértil para novas formas de ativismo, emergência e mapeamento dos modos de subjetivação, analisados a luz das obras de Foucault $(1999 ; 1988)$ e dos estudos transviados. Bento (2017, p. 248), em seu esforço de tradução cultural da teoriaativismo queer, propõe a noção de estudos transviados partindo da interrupção da "reprodução das normas sociais através da incorporação política do outro-abjeto".

Assim, as mídias digitais de comunicação se configuram como lugar onde ressurge o termo POC com novas entonações, implicações e significados, bem como o veículo através do qual se dará a aproximação com o universo estudado. $O$ podcast instaura um meio no qual as pessoas que se identificam como POC podem falar sobre si e por si, enunciarem a si mesmas, o que nos leva à pergunta feita por Foucault (1999, p.08): "[...] o que há, enfim, de tão perigoso no fato de as pessoas falarem e de seus discursos proliferarem indefinidamente? Onde, afinal, está o perigo?". Destacamos aqui as POCs apresentadoras do programa Caio Baptista, Filipe Bortoloto, José Melo e Hilário Júnior.

\section{ANÁLISE DE DISCURSO FOUCAULTIANA}

Foucault (2006) afirma que seus livros podem ser lidos como pequenas caixas de ferramentas para análise do discurso. Dentre essas ferramentas, destaca-se a noção de dispositivo, entendida como uma rede de relações estabelecidas entre elementos heterogêneos, tais como discursos, instituições, o dito e o não dito, estabelecendo a natureza do nexo que pode existir entre eles (FOUCAULT, 2009). Posto isso, entendemos o podcast POC de Cultura como um dispositivo, uma vez que é a base material na qual se inscrevem enunciados que são repetidos e operam na produção de novas verdades. 
O enunciado é compreendido não a partir da individualidade restrita e perecível do enunciador ou como unidade lógica ou gramatical, mas como campo de possibilidades de transcrição e reinscrição que atualizam e fazem emergir, a despeito de seus limiares e limites, um jogo de posições, de sujeitos e objetos. Logo, a questão metodológica passa da interpretação das intenções pessoais do enunciador às condições de enunciação e de produção de verdades de certo regime de poder (FOUCAULT, 2008).

Neste âmbito, a verdade é entendida por Foucault (2009) como o conjunto de procedimentos que permitem pronunciar enunciados que serão considerados enquanto verdadeiros em certo arranjo das relações de poder que configuram o regime de produção de verdade e realidade em questão. Assim, a verdade não existe fora ou sem poder, dado que cada sociedade possui seu regime de verdade, os tipos de discurso que ela aceita e faz funcionar enquanto verdadeiros, e ainda, os mecanismos e instâncias que permitem diferenciar os enunciados verdadeiros ou falsos.

Destarte, o podcast opera a criação de novos discursos sobre as subjetividades POC, sendo discurso um conjunto de enunciados que se apoiam na mesma formação discursiva, ordenada por jogos enunciativos, no cerne dos quais os enunciados não são neutros e independentes, mas funcionam e desempenham papéis em meio a outros discursos. Assim, embora nossa base material primária seja o podcast POC de Cultura, os debates levantados são atravessados por diversos discursos e enunciados de diferentes fontes como textos, músicas, telenovelas etc. (FOUCAULT, 2008).

Nossa tarefa, ao empreender uma análise das formações discursivas com base em Foucault (2008, p. 142), é tratar um conjunto de performances verbais ao nível dos enunciados, "é definir o tipo de positividade de um discurso". Visamos colocar em questão as correlações de força atualizadas nos discursos, onde elas ganham expressão material, visto que é neles que poder e saber se articulam. Logo, o que interessa a tal análise discursiva é questionar a produtividade tática, partindo, por um lado, dos efeitos recíprocos de poder e saber que ela proporciona e, por outro, de "sua integração estratégica, ou seja, que conjuntura e que correlações de forças tornam necessária sua utilização nos confrontos produzidos na vida concreta" (PORTOCARRERO, 1994, p. 52).

\section{ORGANIZAÇÃO DA ANÁLISE DISCURSIVA DOS DADOS}

Partindo do entendimento do funcionamento da análise do discurso sob a perspectiva foucaultiana, organizamos o material levantado no podcast POC de Cultura 
da seguinte maneira: selecionamos 15 episódios do programa a partir de seus títulos e de uma escuta prévia, operando, assim, uma seleção por conveniência dos episódios que se inscreviam mais diretamente à temática do trabalho. Assim, os episódios selecionados foram: 1: O Termo POC!, 4: Crianças Viadas, 6: Sair do Armário, 16: Gays Machistas \& Minas Homofóbicas (com Potocas Podcast), 17: Pink Money, 18: Transexualidade + NãoBinariedade (Com Bryanna Nasck), 25: Autoestima, 27: LGBTS 50+ (Com Fernanda Estima e Beto de Jesus), 28: A Vida Nos Apps De Relacionamento, 35: A Arte Drag (Com Rita Von Hunty), 45: Vai Ter Cultura na Periferia, SIM! (com Perifacon), 48: Amizade Entre Gays, 57: Homofobia Cordial (Com Lorelay Fox), 61: Sexo, Masturbação, Pornografia e Culpa (TW), 78: \#GAYSDOHUMOR - Todo Gay é Engraçado?

A escuta dos episódios foi orientada por algumas das questões que guiaram essa pesquisa, sendo elas: conhecer modos de socialização das POCs em redes digitais de comunicação; caracterizar modos de subjetivação singulares e segmentados em narrativas de produção performativa das POCs; analisar modos de subjetivação em ativismos transviados. A partir da escuta foram catalogados excertos de falas feitas pelos participantes do programa, totalizando 454 trechos. A organização deles foi guiada pelo percurso metodológico proposto por Saraiva (2006), com uma planilha eletrônica que estrutura o material no intuito de facilitar a comparação e a produção de sentido sobre o conjunto. A planilha foi composta por: Enunciados; Emitido por; Temática e Episódio.

$\mathrm{Na}$ coluna de Enunciados reunimos trechos em regularidades enunciativas para mapear suas correlações e multiplicar sentidos, entendendo que o enunciado não existe a não ser fazendo parte de uma série ou conjunto em um jogo enunciativo, estando ele na ordem da raridade, ou seja, tendo em vista suas condições de emergência (FOUCAULT, 2008). Assim, a Análise Discursiva aqui empreendida compreende o enunciado na singularidade de sua situação (GARRÉ; HENNING, 2017).

Já na coluna Emitido por designamos quem enuncia o trecho referido. Com a ressalva de que, embora o autor não seja proprietário e nem criador de seus textos, ele desempenha uma série de funções na ordenação textual (GARRÉ; HENNING, 2017). Assim, Foucault (2009) nos apresenta as quatro principais funções do autor, a primeira ligada ao sistema jurídico e institucional, o qual contém, determina e articula os discursos. A segunda entende que a autoria nasce, é atribuída e se exerce uniformemente para todos os discursos, em diferentes épocas e civilizações. A terceira função diz respeito à não atribuição direta do discurso ao seu produtor, e sim às operações complexas e específicas que produzem esse ser de razão chamado de autor, não se tratando, pois, de 
uma análise pessoal (psicológica ou sociológica) de quem está falando, nem sequer análise comunitária, mas das condições discursivas e seus efeitos de verdade, realidade, ético-políticos. Por fim, a função-autor não remete tão somente ao indivíduo falante, mas dá lugar ao mesmo tempo a várias posições-sujeito que diferentes indivíduos podem ocupar, posições que não são propriedade do sujeito do enunciado (FOUCAULT, 2009).

A coluna da Temática faz referência ao eixo de análise no qual o excerto se encaixa. Este recurso de categorização dos trechos selecionados ajudou a agrupar os discursos que se inscreveram na mesma linha de argumentação nos diferentes episódios em 26 categorias temáticas: Referências POC, Interações POC/norma, Saúde mental POC, POC e o mainstream, Heteroterrorismo reiterado, POC e infância, POC na família, POC e religião, POC e novas gerações, POC e velhices, POC e o feminino, Relação POC/mulher, Sexo POC, Cultura do estupro, Fetichizações, Relacionamentos românticoafetivos POC, POC e gay padrão, Segmentaridades, Militância POC, POC e a comunidade LGBTQIA+, Imaginário de fora da POC, Resquícios do armário, $O$ hétero pela POC, Padrões: em rompimento ou não, Significados POC, Interações entre POCs. Por fim, a quarta coluna na planilha, Episódio, indica o episódio do programa do qual o enunciado provém para fins de sistematização dos dados.

Tendo em vista a grande quantidade de categorias temáticas levantadas no corpus e percebendo que algumas dessas categorias se comunicavam de diversas formas, organizamos metacategorias que agrupassem os excertos de acordo com suas conexões entre si, sendo elas: Cultura e Subjetividades POC, Interações Sexuais/Relacionamentos POC e Resistência e Políticas POC. A seguir, discorremos sobre os resultados encontrados em cada uma delas. Destacamos que essa separação se dá somente a nível de sistematização dos dados da pesquisa, embora todos os enunciados se comuniquem no trabalho de análise das formações discursivas sobre o sujeito POC.

\section{CULTURA E SUBJETIVIDADES POC}

Entendemos subjetividade a partir do campo de produção. Assim, estudar subjetividades implica entender os meios pelos quais ela é forjada, uma vez que não existe constituição do sujeito sem que exista modos de subjetivação, calcados práticas de si que Ihes deem suporte (FOUCAULT, 1998). Butler (2017), a exemplo, retoma essas práticas de si ao trazer a formulação de que não existe identidade de gênero por trás das 
expressões de gênero, uma vez que a performatividade seria a própria identidade, constituída pelas expressões que são entendidas como seus resultados.

De acordo do Foucault (1998), para que se falasse da sexualidade enquanto uma experiência historicamente singular, era necessário ter à disposição instrumentos para análise dos três eixos que a constituem. Estes são: a constituição dos saberes a que se referem, os sistemas de poder relacionados a regulação de suas práticas e as maneiras por meio das quais os indivíduos se reconhecem enquanto sujeitos de uma sexualidade.

É a partir daí que concatenamos um entendimento da produção das subjetividades POC desde a pergunta provocativa sobre como são forjadas as subjetividades POC? Dentro dessa metacategoria se inscreveram originalmente as seguintes categorias temáticas: Referências POC, Interações POC/norma, Padrões: em rompimento ou ainda não, POC e o mainstream, Heteroterrorismo reiterado, POC e infância, POC na família, POC e religião, POC e novas gerações e POC e velhices, Significados POC, POC e o feminino, Relação POC/mulher.

De fato, desde a infância temos algumas pistas que ajudam a pensar tais processos de subjetivação. Aqui destacamos o medo de ser reconhecido enquanto a bichinha, a mulherzinha, a esquisita, que está presente em muitos dos discursos circunscritos nas infâncias POC dentro das diversas instituições que frequenta, tais como escola, família, igreja, sob a prerrogativa da abjeção. Acerca disso, Hilário relata uma conversa com seu pai quando tinha por volta de sete anos de idade, no qual o pai diz: "Se você for um desses cabra safado eu vou colocar você de vestido e vou te colocar na praça pra todo mundo rir da sua cara" (POC DE CULTURA, 2018c).

O bullying surge nos episódios incrementando o cenário de demarcações da abjeção, termo que se refere à "compreensão do lugar reservado socialmente aos corpos sem inteligibilidade social” (BENTO, 2017, p.49). No podcast, Filipe conta o seguinte episódio: "o grupo na escola ia dançar ragatanga mas eu não queria me envolver, mesmo eu amando Rouge" (POC DE CULTURA, 2018b). A emergência enunciativa da noção de bullying aparece e ganha preponderância no podcast, sendo aqui entendido como um dispositivo que produz formas de ver e dizer um problema. Assim, pensamos nele como uma rede tecida entre elementos heterogêneos (discursos, instituições, regulamentações, leis, decisões administrativas, enunciados científicos e proposições morais) sobre a violência entre pares no contexto escolar/educacional (BARROS, 2017).

A disciplina psicológica se destaca como um dos elementos que tecem 0 entendimento do bullying e responde a ele enquanto especialista, demarcando-o em uma 
interioridade a qual Butler (2017) nos alerta ao apontar a inviabilidade de se questionar o sistema psicologizante individualizante utilizando as mesmas categorias que nos interessa minar. Bento (2017) afirma, ainda, o caráter asséptico do termo, que não revela o heteroterrorismo vivenciado por crianças e adolescentes, reiterado por agressões verbais e físicas contra meninos femininos e meninas masculinas. Dessa forma, a despeito do uso do termo bullying no podcast, o que tratamos aqui é de preconceito e discriminação, reflexo da positividade da heterossexualidade compulsória e violências nela implicadas.

Além disso, o heteroterrorismo acaba por tensionar e aproximar POCs e mulheres. A respeito disso, coloca Caco: "o primeiro momento no colégio foi essas coisas assim de dançar no recreio. [...] Eu passei a andar muito com as meninas então eu fui naturalmente caminhando para ser a criança viada ali muito latente" (POC DE CULTURA, 2018b).

Ademais da aproximação por identificação, temos com a figura da mulher o palco de algumas descobertas no campo sexual, que podem ser entendidas como descobertas por conveniência e afinidade. José comenta: "meu primeiro beijo hetero eu estava com 13 anos e estava todo mundo perdendo o bv [...] uma amiga do meu irmão falou para ele que queria ficar comigo. Foi horroroso" (POC DE CULTURA, 2018b). Nesse momento, os participantes do programa dizem surgir a cogitação de uma bissexualidade que para eles era irreal, uma vez que não se referia a suas identificações enquanto desejo sexual, mas sim como uma das maneiras encontradas de fugir novamente do que seria o anormal, o não digno de amor, ou ainda, de ter um traço reconhecidamente masculino. "Acho que na verdade a gente meio que fica querendo colocar bi pra tentar salvar do perigo de ser gay", disse Filipe (POC DE CULTURA, 2018b).

Vemos que o medo acaba por ser uma das forças que produz a aproximação POC e mulher, como alvos de sujeição e violência sistêmica. Entretanto, a adjacência com o feminino coloca a POC em um rompimento deflagrado com as pressões heterossexistas de identificação com o masculino, provocando o temor pela descoberta e destacando a relação de poder relatada por Sedgwick (2007, p.38) "daqueles que pensam que sabem algo sobre alguém que pode não sabê-lo". Acerca disso, Caco comenta que é "muito constante essa coisa de você pensar como seria a sua vida se seus pais não te apoiassem e você traça um paralelo do tipo se eles não me apoiarem e me expulsarem de casa eu tenho que fazer $x, y, z$ pra sobreviver." (POC DE CULTURA, 2018c).

Sedgwick (2007) pensa uma epistemologia do armário como um armário de vidro, que funcionaria como segredo aberto, na medida em que é um segredo conhecido por aqueles que estão em volta de quem o esconde. Seja por estar em relações que 
bagunçam a ordem do desejo heterossexual, seja por performar atributos de gênero incoerentes com a ordem do sexo substantivo (BUTLER, 2017), o armário de vidro autoriza o insulto ou estabelece relações afetuosas cuja utilidade faz parte da lógica do assimétrico e do espetacular (SEDGWICK, 2007), como traz Hilário:

Perto da casa da minha vó tinha um salão da Jacy cabelereira, Jacy era uma travesti, minha vó só cortava belo com Jacy, ela não tinha tv e ia assistir novela na casa da minha vó.[...] Quando Jacy levantava pra ir embora meu pai começava a brigar com minha vó e com todo mundo, como é que deixa essa pessoa entrar aqui? (POC DE CULTURA, 2018c).

Dessa forma, a denegação da feminilidade é paradoxalmente uma das formas primeiras de aproximação entre POC/feminino. Posteriormente, a desconstrução desse esquema de denegação irrompe um novo lugar de não só aceitação desse feminino, mas de exaltação. Esse lugar tem uma função micropolítica muito importante de deslocar a posição da bicha afeminada para uma positivação, isso porque tanto dentro da comunidade LGBTQIA+ como fora, a bicha afeminada é ainda vista de forma pejorativa. Sobre isso, diz Filipe: "ninguém gosta de assumir que é passivo, passivo é errado, é submisso, é bicha afeminada, e bicha afeminada é errado." (POC DE CULTURA, 2019g).

Percebe-se como a ideia negativada do gay afeminado permeia as mais variadas instituições, dentre elas a família, nas quais o aspecto religioso aparece muitas vezes como plano de fundo. Filipe comenta sobre o seu relacionamento com sua mãe após sua saída do armário: "dali foi por água abaixo, ela tentou me exorcizar, levou igreja em casa pra fazer culto comigo, me levou pra psicólogo, tentava conversar com os psicólogos antes pra falar de cura gay" (POC DE CULTURA, 2018c). No que tange a tal tema, Foucault (1988) nos atenta para o fato de, a partir do século XVIII, as mínimas manifestações da sexualidade passam a ser focalizadas pelos poder-saber, desde onde reverberam na veiculação de modos de sujeição e esquemas de conhecimentos, a exemplo no enunciado acima: padre/pecador/exorcismo, psicólogo/doente/cura.

Nas crenças religiosas, que no programa aparecem ligadas principalmente ao catolicismo, a religiosidade funciona como um dispositivo de culpabilização que permeia as práticas sexuais desde a infância e adolescência. A respeito disso, Hilário comenta: "estava me envolvendo com um menino próximo da renovação, eu fazia parte da renovação e dizia estou em pecado, estava me odiando." (POC DE CULTURA, 2018c). Percebe-se, como o que se entende como descoberta sexual POC é perpassada por questões que colocam a POC em um lugar de suja, de má, de indevida, de anormal. 
Entretanto, as relações fomentadas pela pastoral cristã operam também de maneiras menos diretas e incisivas, mas não menos violentas. Assim, o discurso que antes preconizava a morte aos gays se transforma em uma ajuda fictícia supostamente benevolente, como comenta Filipe: "lembro muito da minha prima batendo na minha janela e falando assim: Filipe, a gente está aqui pra te ajudar, a gente está aqui pra tirar isso de você, pra fazer você voltar pro caminho do bem" (POC DE CULTURA, 2019f).

A década de 1990 é mencionada com frequência no podcast por ser a época em que os apresentadores vivenciaram suas infâncias e adolescências. Eles comentam que nesse período as referências de gays na mídia tradicional eram bastante reduzidas e caricatas. Somando esse fato ao contexto cristão retratado por Filipe, ele relata que "a gente que nasceu nos anos 90 não tinha referência gay e fica achando que é o grande pecador do mundo, você tem só 12 anos e com uma preocupação gigantesca em ser descoberto" (POC DE CULTURA 2019g).

Vera Verão encarna a caricatura da retratação gay nas mídias tradicionais de até então. Vemos uma bicha engraçada, com uma comicidade centrada principalmente na sua performance gay extravagante, expansiva, sempre causando confusão e falando alto, forma praticamente única de visibilidade gay assumida na mídia da época. Caco comenta sobre como isso lhe soava: "era muito o medo do tipo não quero ser vinculado a imagem da Vera Verão porque eu não quero sofrer esse tipo de preconceito, eu não quero ter que responder o 'bicha não', porque na hora que falar o 'bicha não' eu não vou saber o que falar" (POC DE CULTURA, 2018c). Se Vera, com sua talentosa e marcante performance, lidava com comentários depreciativos em relação a sua performance, o que esperar de uma POC que a tinha enquanto referência?

A mudança progressiva e tortuosa desse contexto com a inserção da população LGBTQIA+ em espaços nas mídias é acompanhada de sua potencialização enquanto público consumidor. Nesse sentido, o Pink Money surge nas conversas durante o podcast principalmente relacionado ao capital movimentado pelo público LGBTQIA+. Sobre isso, Filipe diz "é um termo que abrange o poder de compra da comunidade LGBT, que demorou muito pra ser entendido como nicho". Por que a população LGBTQIA+ demorou a ser entendida enquanto nicho de mercado?

O lugar do público LGBTQIA+ agora como compradores em potencial e movimentadores de streaming deu lugar a uma explosão de conteúdos produzidos por e para LGBTQIA+. Espaços não raro utilizados para trazer tensionamentos e discussões 
para a comunidade no geral, mexendo com as normas e convidando de forma sutil para uma aproximação com o rompimento de regras heterocentradas de sexo e gênero.

A chegada LGBTQIA+ ao mainstream 1 é apontada no podcast como resultado de uma comunidade que busca um lugar de pertencimento, como diz Filipe:

Você vê gente que não tem apoio da família, do ciclo familiar, e consegue transformar isso em uma persona e na hora que põe uma roupa e assume um outro nome vira uma pessoa extremamente feliz e engraçada, isso é uma coisa de muitas drags. [...] Sintoma de uma comunidade que precisa se virar para se sentir amada, aplaudida etc. (POC DE CULTURA, 2020).

Entretanto, não falamos de uma aliança amigável e harmônica entre a comunidade LGBTQIA+ e a mídia/marketing. A convidada ao programa Rita Von Hunty, afirma: "o que a gente está vivendo é: olha, nós somos uma marca milituda, mas a gente não vai se associar a nenhum militante, a militância só pra vender" (POC DE CULTURA, 2019d). Na contramão dessa inserção no mainstream, temos a menção no podcast de dados do relatório do Grupo Gay da Bahia (OLIVEIRA; MOTT, 2020) de que a cada 26 horas um LGBTQIA+ é assassinado ou se suicida vítima da LGBTfobia, confirmando o Brasil como campeão mundial na morte dessa população. Ao funcionar sob a lógica neoliberal, onde o poder financeiro é central, a mídia/marketing acaba por deixar de fora uma grande parcela de pessoas, que continuam sendo mortas e brutamente violentadas.

Apesar das diversas mudanças percebidas na retratação da POC na mídia, uma característica que persiste é a comicidade. Atualmente, com uma busca na internet e a partir das falas no podcast, podemos catalogar diversos personagens cômicos feitos por homens gays, com o enredo atrelado principalmente a imagem da POC engraçada e extrovertida e da travesti. Isso nos leva a pensar na relação da POC com o humor, que aparece como forma de inclusão. Caco afirma: "essa narrativa de sempre recorrer aos pequenos acessos pra chegar num resultado final que é a aceitação é muito cruel porque ela continua sendo um tabu e uma dificuldade" (POC DE CULTURA, 2020). Ser engraçado para a POC aparece como possibilidade de amabilidade e de pertencimento.

O humor favorece, por um lado, uma aproximação da POC com a norma e, por outro, com sua marginalidade e abjeção. Em consequência disso, relação de POCs com as mulheres muitas vezes recaem no que foi chamado no programa de relação de PET. Caco afirma que o termo veio "da hipérbole do homem gay que é engraçado, tem muitas referências, é muito culto, mas que é usado como PET porque ele só serve quando é

\footnotetext{
${ }^{1}$ Corrente dominante, com relação às mídias.
} 
engraçado" (POC DE CULTURA, 2020). Percebe-se o estigma implicado nessa relação, que acaba por anular diversos aspectos da existência POC, como menciona Filipe sobre o personagem Crô, da telenovela Fina Estampa, diz ele: "é por isso que existem os PETs, gays que não tinham vida, amor, economia, vida social, o tempo inteiro para escolher a roupa pra madame" (POC DE CULTURA, 2020).

É por expor frequentemente o seu rompimento com a norma que a POC encontra no humor uma forma de enfrentamento/sobrevivência, uma vez que ele the assegura um lugar de aceitabilidade. Entretanto, nem todos os gays estão nessa posição, o que dá lugar a outras formas de interatividade junto à norma. Sobre isso, José comenta: "para LGBT's que são padrões não existe esse peso para ser engraçado e as pessoas não lingam que eles não sejam engraçados. Pessoas padrões elas só precisam ser padrões, eles não precisam ser mais nada para serem bem-quistas" (POC DE CULTURA, 2020).

A esse ponto poderíamos falar de uma certa passabilidade que aparece sorrateira no contexto POC. Entende-se esse termo relacionado com a perspectiva da perfomatividade de gênero, assim, "dispõe um conjunto de atos regulados e repetidos que asseguram uma imagem substancial de gênero no registro de uma matriz heterossexual e cisgênera" (PONTES; SILVA, 2018, p.407). Nesse sentido, a convidada Bryanna² comenta: "a passabilidade é uma segurança muito grande dentro da nossa sociedade, no momento que você é vista enquanto uma pessoa cis as pessoas te respeitam pelos seus pronomes, respeitam sua identidade" (POC DE CULTURA, 2019a).

Uma vez que a proximidade com a norma produz desejos para com ela, gays masculinos querem gozar com gays normativos, sob a justificativa do gosto. Nesse sentido, o convidado do programa Beto afirma: "quando eu falo: ah, mas esse é meu gosto. Gosto é o caralho, gosto é construção sociocultural, e você recebe o tempo inteiro informações que vai te fazendo o teu gosto" (POC DE CULTURA, 2019b). No mesmo episódio, em relação a velhices e em uma discussão sobre moldes familiares, Caco comenta: "as pessoas já aceitaram que elas são gays, mas elas ainda tão procurando o ideal da família perfeita, ou o ideal do conseguir não ficar sozinha, ter uma velhice perfeita também é tipo não vou morrer sozinha etc." (POC DE CULTURA, 2019b). É na normatividade hétero que se busca essa ideia fictícia de perfeição, a mesma que violentou e violenta LGBTQIA+ de diferentes formas, dita um ideal de vida socialmente

\footnotetext{
2 Mulher trans não binária. Produtora de conteúdo online no Youtube e outras redes sociais onde conversa sobre sexualidade, gênero, saúde mental e coisas do dia a dia.
} 
saudável e pune aqueles que dela querem escapar no escopo do que Butler (2017) chamada de herteronormatividade compulsória.

As novas gerações aparecem no podcast com uma certa esperança em relação aos apresentadores que viveram suas infâncias/adolescências por voltas dos anos 1990/2000. Caco diz: "não imagino hoje em dia uma criança ou adolescente como a gente teve desse plano de fuga, do tipo, ah, se der errado eu tenho ABCD de coisas pra fazer" (POC DE CULTURA, 2018c). Essa é uma das relações que atravessam e constituem o campo de produção de subjetividades POC e sugerem a emergência de novas subjetividades que vêm do tensionamento e da desacomodação das relações de poder hegemônicas. O que não quer dizer que já não existam tais relações de poder, uma vez que em nenhum lugar estamos isentos, fora ou livres delas (FOUCAULT, 2004).

\section{INTERAÇÕES SEXUAIS/RELACIONAMENTOS POC}

$\mathrm{Na}$ sequência das problematizações do campo de constituição de subjetividades POC, nos dedicamos à tematização das interações sexuais e relacionamentos POC. Dentro dessa metacategoria de análise agrupamos as seguintes categorias temáticas: Sexo POC, Cultura do estupro, POC e gay padrão, Fetichizações e Relacionamentos romântico-afetivos POC.

Os apresentadores do podcast comentam sobre uma série de estratégias utilizadas, ainda na infância, por eles para terem acesso aos meios que lhes suscitavam prazer. Dentre as táticas criadas podemos listar: assistir escondido ao Cine Band, na esperança de ver um pênis; se masturbar pensando nos modelos do programa do João Cleber; dormir com a foto do Paulo Zulu na cueca; ver os dançarinos sem camisa dos programas de auditório da TV e a pornografia (POC DE CULTURA, 2019g).

Juntamente às questões sexuais, a baixa autoestima aparece com frequência nos relatos, sobretudo no início da adolescência. São recorrentes os sentimentos descritos em relação à inadequação ao que é desejado dentro da comunidade G, Bryanna, comenta: "não me sentia desejada de nenhuma forma, e isso ficava muito óbvio porque a comunidade gay super gordofóbica, super querendo o estereotipo do macho branco loiro dos olhos claros, e eu era só uma POC louca" (POC DE CULTURA, 2019a).

A baixa autoestima e o sentimento de inadequação, de não desejabilidade, nos leva a outro dado levantado no programa, sobre o qual Bryanna, Hilário e Filipe afirmam que tiveram suas primeiras experiências sexuais com pessoas mais velhas e em 
contextos que sugerem relações abusivas. "Meu primeiro namorado tinha 24 anos e eu tinha 14 anos" diz Bryanna, "eu lembro que eu namorei uma pessoa que tinha 45 e eu tinha 17" diz Hilário e "A minha primeira vez foi eu tinha 15 anos eu fiquei com dois caras de 29, eles meio que me obrigaram" diz Filipe (POC DE CULTURA, 2019a).

Observa-se a relação do abuso com a abjeção e com o fato de não se sentir amado, pertencente ou desejável. Isso faz com que situações abusivas sejam aceitas à medida em que surgem como uma forma possível de se sentir amável e afetivamente viável. Bryanna comenta: "me sentia grata por ter uma pessoa que quer me usar de alguma forma. [...] Isso vai te quebrando que você fala: amor existe mesmo? [...] Será que eu posso viver um amor ou isso é uma exclusividade de pessoas cis branco heterossexual?" (POC DE CULTURA, 2019a).

Neste contexto, são relatadas situações de abuso sexual, atreladas também à experiência e aprendizagem clandestina acerca do sexo. Caco afirma:

Eu fui vítima de abuso, eu não sou único aqui no POC que viveu isso. Eu fui vítima de dois abusos, nisso eu comecei a perceber como homem gay também não sabe transar porque foi o lance de força, de querer botar força e de achar que a coisa é na força e na pressa e acho que as coisas não funcionam assim, a gente está sempre caindo num flerte muito próximo da cultura de estupro (POC DE CULTURA, 2019g).

É a partir desse espaço marginal de aprendizagem sobre o sexo que a indústria pornô produz uma série de inseguranças quanto ao corpo e performances sexuais, tendo em vista a propagação de performances estereotipadas e heteronormatizadas. " $A$ pornografia é machista. Quando a mulher assiste o pornô ela aprende que tem que ser submissa e o homem a ser viril, performance, pau no joelho" (POC DE CULTURA, 2019g), comenta Filipe. Esse cenário exclui diversas formas de experimentações sexuais, dentre elas as práticas de interação sexual não penetrativas, trazida no podcast como Gouinage $^{3}$, e outras formas de sexo.

O movimento Gouine é aqui entendido em relação a reapropriação do dispositivo pornográfico que o transforma em um espaço de subversão, no qual a sexualidade não se restringe aos genitais, em exercícios de contra-biopolítica (PRECIADO, 2014). Em Foucault (1988) o sexo se encontra na articulação entre os dois eixos a partir dos quais se desenvolveu a tecnologia política da vida, sendo elas as disciplinas anatomopolíticas do

\footnotetext{
${ }^{3}$ Como são conhecidos aqueles que obtém prazer sexual sem penetração. Sexo Gouine.
} 
corpo e o biopoder, a regulação das populações. Assim, a categoria de sexo é construída a serviço de um sistema de sexualidade reprodutiva e reguladora.

Além disso, o lugar do homem macho no pornô gay coloca a masculinidade/ativa em um lugar de privilégio em relação a feminilidade/passiva, ainda que isso não seja regra e essa relação macho/ativo, fêmea/passiva se dissolva nas práticas sexuais POC. Coelho (2009) aponta que o movimento feminista anti-sexo entende a pornografia não somente como representação da submissão feminina (englobada a passividadefeminilidade) aos desejos masculinos, mas sendo a própria pornografia produtora dessa realidade. Sobre o estereótipo da masculinidade (macho) ativa, Filipe comenta: "mas rola muito isso, porque a gente aprende que homem que come bem é homem bruto". (POC DE CULTURA, 2019g).

A subversão das relações homem-mulher, macho-fêmea, passivo-ativo, dominadordominado são postas em desconstrução no movimento que Paul Beatriz Preciado (2014, p.27) chama de contrassexualidade, que tem por tarefa identificar os espaços errôneos, as falhas da estrutura do texto (bichas, hermafroditas, sapas, caminhoneiras, loucas) e "reforçar o poder dos desvios e derivações com relação ao sistema heterocentrado".

Um dos espaços utilizados com frequência na busca de sexo casual são os aplicativos de relacionamentos, que substituíram a antiga arte de trutuar, termo trazido no programa e que significa buscar pessoas na rua com o olhar. Esse espaço traz consigo novas questões, como o medo frente à violência de ataques homofóbicos, sobre o qual Filipe comenta: "sempre que eu chamava alguém do aplicativo pra ir em casa eu sempre colocava uma faca embaixo do travesseiro ou embaixo do coxão, pra me proteger, eu morava sozinho e tinha medo" (POC DE CULTURA, 2019c).

O que se tenciona afinal é a positivação da relação entre POCs e a ruptura com o desejo do desejo da norma e ainda sua separação enquanto referência (BENTO, 2017). Isso porque os moldes de relacionamentos gays ainda privilegiam aspectos que são referentes as relações heterossexuais. Assim, a criação de algo que rompa com questões como fidelidade monogâmica, ativo/passivo, homem e mulher da relação, ainda são desafios, tensionamentos e rupturas que dizem respeito às políticas de resistência POC, última metacategoria de análise, disposta a seguir. 


\section{RESISTÊNCIA E POLÍTICAS POC}

Essa última metacategoria discorre um pouco sobre as rupturas, criações e ressignificações que implicam formas de ativismo POC mapeadas a partir da escuta do podcast POC de Cultura, e abrangem as categorias: Segmentaridades, Militância POC, POC e a comunidade LGBTQIA+, Imaginário de fora da POC, Resquícios do armário, O hétero pela POC, Padrões: em rompimento ou ainda não, Significados POC, Interações entre POCs. Como mencionado no início do trabalho, embora o texto seja dividido em três metacategorias para fins de organização, os enunciados conversam em diferentes pontos, evidenciando suas interrelações nas práticas discursivas que moldam a constituição e compreensão da realidade (GARRÉ; HENNING, 2017).

Retomando o contexto dos aplicativos de relacionamentos para gays, no podcast são descritos como espaços de reprodução de preconceitos e estigmas, reiteração de padrões hegemônicos de beleza e masculinidade. A partir disso, se discute um novo investimento de desejos que desacomodem essa reprodução, por exemplo, do desejo único fictício pelo gay marcado como padrão, aquele que tem sua performatividade de gênero heterocentrada, embora também rompa com a coerência sexo, gênero, prática sexual, desejo (BUTLER,2017).

Destaca-se a importância da produção de algo novo, que rompa não somente com a coerência forçosa entre sexo-gênero-desejo, mas também com o desejo por performances heterocentradas (macho/ativo/bruto). É nesse sentido que comenta Caco: "você precisa entrar em contato com outras realidades e buscar essa visão mais ampla, porque querendo ou não, se você não fizer isso, você vai se relacionar sempre com as mesmas pessoas" (POC DE CULTURA, 2019g). Ou seja, a ampliação do desejo a outras performances e corporeidades distantes do padrão: afeminadas, gordas, negras etc.

Dessa forma, se engendra, por exemplo, um sujeito afeminado que já não tem que abdicar do amor e do desejo de ser desejado ou bem tratado, aquém da violência, da agressividade, da brutalidade e da passividade que não seja estritamente acordada. Entretanto, existem, ainda, diversos atravessamentos que multiplicam as possibilidades de existência POC, o que inviabiliza, por exemplo, falarmos em atributos totalizantes que definam todos aqueles que aí se inscrevem.

O podcast destaca várias condições de vida e singularidades que influenciam as vivências POC, dentre elas: questões de raça, econômicas (pobreza, mobilidade urbana, condições de moradia), condições físicas (pessoa com deficiência, gordos e gordas), 
aspectos familiares (religiosidade), dentre outras. Nesse sentido, Caco afirma: "o meio que você tá vai dizer muito sobre como isso vai ser" (POC DE CULTURA, 2018a).

A noção de que toda POC é gay, mas nem todo gay é POC, além de diversas outras diferenciações que existem no mundo gay, muitas vezes acaba criando um ambiente separatista não só nele, mas no meio LGBTQIA+ em geral. Por isso, Caco faz o apelo a uma integração maior da comunidade, comenta ele: o "tipo gay Regina George precisa parar, cultura do shade 4 precisa parar, e a gente precisa começar a se unir de uma forma mais válida mesmo" (POC DE CULTURA, 2019e).

O que vemos é uma movimentação política que surge nas redes sociais, por meio de um podcast feito por POCs, que não é direcionado somente a POCs. O tensionamento de questões e a ampliação e difusão do acesso a elas, coloca o conteúdo produzido no programa em um lugar importante na criação de uma nova realidade, principalmente de auto-enunciação. A apropriação e ressignificação da abjeção é o ponto central nisso, já que o que antes era insulto agora é mecanismo de ativismo e empoderamento.

\section{POC E AS TEORIAS/ATIVISMO TRANSVIADOS}

A apropriação de um termo antes pejorativo e a crítica às relações binárias e de gênero a partir de performances fluidas aproximam a POC dos estudos/ativismo Queer/transviados. Dessa maneira, se inscreve em práticas que contestam binaridades sexuais e de gênero, desnaturalizam bioidentidades e enfatizam relações de poder que interpretam as estruturas subjetivas e objetivas da vida social e se atenta à dimensão da agência humana (BENTO, 2017).

Em uma conferência na Califórnia, em fevereiro de 1990, Teresa de Lauretis empregou a denominação Queer Theory para contrastar o empreendimento queer com os estudos gays e lésbicos (JAGOSE, 1996). Mais recentemente, Louro (2004) localizou o Queer como um lugar de "entre lugares" (p.8), de ambiguidades e incômodo, na medida em que desafia as normas sociais regulatórias, constituindo-se enquanto um jeito de pensar e de ser que não almeja o centro e nem o quer enquanto referência, ou seja, é o excêntrico que não deseja a aceitação ou a tolerância. Ou ainda, nas palavras de Bento (2017) refere-se ao outro-abjeto que olha para o seu senhor e diz: "Eu não desejo mais teu desejo [...] Quero uma vida em que eu possa dar pinta, transar com quem eu tenha vontade, ser dona(o) do meu corpo" (BENTO, 2017, p. 248).

\footnotetext{
${ }^{4}$ Cultura entre gays de zombar, alfinetar, criticar, advindo da cultura drag queen.
} 
Segundo Safatle (2015), o termo Queer surge na língua inglesa no século XVI designando algo estranho, peculiar, excêntrico e no século XIX passa a ser utilizado como xingamento a homossexuais e outros que tivessem práticas sexuais aparentemente desviantes. No final da década de 1980, grupos LGBT's começam a se apropriar da palavra e a desativar o seu caráter pejorativo (SAFATLE, 2015). Esse percurso nos parece análogo ao recente processo de ressignificação do termo POC no Brasil, dado o esforço para que a POC saia do gueto não o negando, mas se apropriando dele e rompendo com a coerência hétero-compulsória.

Os atributos POC ao se aproximarem do feminino e performarem uma fluidez, aparecem em desconformidade com os modelos sequenciais e causais de inteligibilidade, que produzem o que Butler vai chamar de substância permanente e fictícia (homem e mulher). De acordo com ela, "a regulação binária da sexualidade suprime a multiplicidade subversiva de uma sexualidade que rompe com as hegemonias heterossexual, reprodutiva e médico-jurídica" (BUTLER, 2017, p.47). Essa desorganização desvela o caráter fictício e superficial contingencialmente criado pela regulação de atributos para a produção fictícia de um eu com traços de gênero ou de uma substância permanente, uma vez que resistem e denunciam a apreensão de uma estrutura pronta de "substantivos primários e adjetivos subordinados" (BUTLER, 2017, p.55).

A autora traz a perspectiva de que o desejo homossexual rompe com a heterossexualidade compulsória uma vez que o liberta desta marcação preliminar dos sexos. Entretanto, é difícil pensar na democratização da decisão POC em romper com seus adjetivos subordinados, ou seja, nem toda POC decide desfazer gênero. Isso se dá em relação a uma série de condições de vida e singularidades que interferem em como se produzem os sujeitos POCs, assim, parafraseando Butler (2017): se alguém é POC, isso certamente não é tudo que alguém é.

\section{CONSIDERAÇÕES FINAIS}

A ressignificação do termo POC através das redes digitais de informação e comunicação trouxe consigo diversas implicações e tensionamentos que a colocou em proximidade com os estudos/ativismo Queer e Transviados (BENTO,2017) no Brasil. Tal movimento produz efeitos ético-políticos de ressignificação das experiências POC.

Dessa forma, o Podcast POC de Cultura faz emergir um espaço de autoenunciação política e um dispositivo na criação de novas verdades. Assim, partindo da 
ideia de que a verdade é produzida (FOUCAULT, 1999), os enunciados veiculados pelo podcast se inscrevem na ordem do discurso aceito como verdadeiro ao serem repetidos e transmitidos constantemente, indicando novas maneiras de fazer, se comportar, consumir e desejar (GARRÉ; HENNING, 2017). Assim, tensionam, disputam narrativas, em favor de fazer legitimar performatividade de gênero, antes abjetas e silenciadas.

Com isso, acompanhamos a luta política evidenciada pelo podcast na positivação do termo POC, rompendo com as bioidentidades, denunciando as incoerências forçadas por uma heterossexualidade compulsória e se constituindo apesar de um gênero substantivo fictício. Assim, as expressões de gêneros experimentadas pela POC são em si suas identidades, construídas a partir de suas performances (BUTLER,2017).

\section{REFERÊNCIAS}

BARROS, J. P. P. Dispositivo-Bullying e Governamentabilidade Securitária: Diálogos com o pensamento de Michel Foucault. Dialectus: Revista de Filosofia, Ceará, n. 11, p.5068, ago./dez. 2017. Disponível em: https://doi.org/10.30611/2017n11id31000. Acesso em: 24 de jul. 2020.

BENTO, B. Transviad@s: gênero, sexualidade e direitos humanos. Salvador: EDUFBA, 2017.

BRUNO, F. Máquinas de ver, modos de ser: vigilância, tecnologia e subjetividade. Porto Alegre: Sulina, 2013.

BUTLER, J. Problemas de gênero: feminismo e subversão da identidade. $15^{\circ}$ ed. Rio de Janeiro: Civilização Brasileira, 2017.

COELHO, S. Por um feminismo queer: Beatriz Preciado e a pornografia como pretextos. Ex aequo, Vila Franca de Xira, n. 20, p. 29-40, 2009. Disponível em $<$ http://www.scielo.mec.pt/scielo.php?script=sci_arttext\&pid=S0874$55602009000200004 \&$ lng=pt\&nrm=iso >. acesso em 24 jul. 2020.

FOUCAULT, Michel. História da sexualidade I: A vontade de saber. Rio de Janeiro: Edições Graal, 1988.

FOUCAULT, Michel. História da Sexualidade II: O uso dos prazeres. Tradução de Maria Thereza da Costa Albuquerque. Rio de Janeiro: Edições Graal, 1998.

FOUCAULT, Michel. A Ordem do Discurso: aula inaugural no Collège de France, pronunciada em 2 de dezembro de 1970. 15. ed. São Paulo: Loyola, 1999.

FOUCAULT, Michel. Michel Foucault, uma entrevista: sexo, poder e a política da identidade. Verve - Revista do Nu-Sol, São Paulo: Pós-Graduação em Ciências Sociais, Pontifícia Universidade Católica, n. 5, p. 260-277, 2004.

FOUCAULT, Michel. Dos suplícios às celas. In: POL-DROIT, Roger. Michel Foucault entrevistas. São Paulo: Graal, 2006. 
FOUCAULT, Michel. A arqueologia do saber. Trad. Luiz Felipe Baeta Neves. 7. ed. Rio de Janeiro: Forense Universitária, 2008.

FOUCAULT, Michel. Ditos e escritos III: Estética: literatura e pintura, música e cinema. MOTTA, Manoel Barros da (Org.). Tradução de Inês Autran Dourado Barbosa. Rio de Janeiro: Forense Universitária, 2009.

GARRÉ, B.; HENNING, P. Travessias de uma pesquisa: mapeando algumas ferramentas metodológicas da análise do discurso em Michel Foucault. Conjectura: Filos. Educ., Caxias do Sul, v. 22, n. 2, p. 300-319, maio/ago. 2017.

JAGOSE, A. Queer Theory - an introduction. New York: New York University Press, 1996.

LEITE, F. T. Metodologia Científica: métodos e técnicas de pesquisa: monografias, dissertações, teses e livros. Aparecida: Ideias \& Letras, 2008.

LOURO, G. L. Um corpo estranho: ensaios sobre sexualidade e teoria queer. Belo Horizonte: Autêntica, 2004.

MAFORT, M.; RAMOS, L; FERNANDES-SANTOS, C. Podcast como Estratégia de Inclusão no Ensino Superior. SocArXiv Papers. 2019. Disponível em:

10.31235/osf.io/4vypq. Acesso em: 10 jul. 2020.

OLIVEIRA, J. M. D.; MOTT, L. Mortes violentas de LGBT+ no Brasil - 2019: Relatório do Grupo Gay da Bahia. 1. ed. Salvador: Editora Grupo Gay da Bahia, 2020.

PRECIADO, P. B. Manifesto Contrassexual. Políticas subversivas de identidade sexual. São Paulo: $n-1$ edições, 2014.

POC DE CULTURA. O Termo POC! [Locução de]: Baptista, C., Bortolotto, F., Melo, J., Júnior, H. São Paulo, 25 set. 2018a. Podcast. Disponível em:

https://pt.player.fm/series/poc-de-cultura. Acesso em: 10 de maio de 2020.

POC DE CULTURA. Crianças Viadas [Locução de]: Baptista, C., Bortolotto, F., Melo, J., Júnior, H. São Paulo, 10 out. 2018b. Podcast. Disponível em:

https://pt.player.fm/series/poc-de-cultura. Acesso em: 14 de abril de 2020.

POC DE CULTURA. Sair do Armário [Locução de]: Baptista, C., Bortolotto, F., Melo, J., Júnior, H. São Paulo, 01 nov. 2018c. Podcast. Disponível em:

https://pt.player.fm/series/poc-de-cultura. Acesso em: 18 de abril de 2020.

POC DE CULTURA. Transexualidade + Não-Binariedade (Com Bryanna Nasck) [Locução de]: Baptista, C., Bortolotto, F., Melo, J., Júnior, H. São Paulo, 05 fev. 2019a. Podcast.

Disponível em: https://pt.player.fm/series/poc-de-cultura. Acesso em: 21 de abril de 2020.

POC DE CULTURA. LGBTS 50+ (Com Fernanda Estima e Beto de Jesus) [Locução de]: Baptista, C., Bortolotto, F., Melo, J., Júnior, H. São Paulo, 09 abr. 2019b. Podcast.

Disponível em: https://pt.player.fm/series/poc-de-cultura. Acesso em: 29 de abril de 2020.

POC DE CULTURA. A Vida Nos Apps De Relacionamento [Locução de]: Baptista, C., Bortolotto, F., Melo, J., Júnior, H. São Paulo, 16 abr. 2019c. Podcast. Disponível em: https://pt.player.fm/series/poc-de-cultura. Acesso em: 9 de maio de 2020.

POC DE CULTURA. A Arte Drag (Com Rita Von Hunty) [Locução de]: Baptista, C., Bortolotto, F., Melo, J., Júnior, H. São Paulo, 04 jun. 2019d. Podcast. Disponível em: https://pt.player.fm/series/poc-de-cultura. Acesso em: 9 de maio de 2020. 
POC DE CULTURA. Amizade Entre Gays [Locução de]: Baptista, C., Bortolotto, F., Melo, J., Júnior, H. São Paulo, 22 set. 2019e. Podcast. Disponível em: https://pt.player.fm/series/poc-de-cultura. Acesso em: 6 de maio de 2020.

POC DE CULTURA. Homofobia Cordial (Com Lorelay Fox) [Locução de]: Baptista, C., Bortolotto, F., Melo, J., Júnior, H. São Paulo, 15 out. 2019f. Podcast. Disponível em: https://pt.player.fm/series/poc-de-cultura. Acesso em: 6 de maio de 2020.

POC DE CULTURA. Sexo, Masturbação, Pornografia e Culpa (TW) [Locução de]: Baptista, C., Bortolotto, F., Melo, J., Júnior, H. São Paulo, 12 nov. 2019g. Podcast. Disponível em: https://pt.player.fm/series/poc-de-cultura. Acesso em: 10 de maio de 2020.

POC DE CULTURA. \#GAYSDOHUMOR - Todo Gay é Engraçado? [Locução de]: Baptista, C., Bortolotto, F., Melo, J., Júnior, H. São Paulo, 10 de mar. 2020. Podcast. Disponível em: https://pt.player.fm/series/poc-de-cultura. Acesso em: 9 de maio de 2020.

PORTOCARRERO V. Filosofia, história e sociologia das ciências. Rio de Janeiro: Editora Fiocruz; 1994.

PONTES, J. C.; SILVA, C. G. Cisnormatividade e passabilidade: deslocamentos e diferenças nas narrativas de pessoas trans. Periódicus, Salvador, v. 1, n. 8, nov.2017abr. 2018. Disponível em http://dx.doi.org/10.9771/peri.v1i8.23211. Acesso em 24 jul 2020.

SAFATLE, V. Posfácio. Dos problemas de gênero a uma teoria da despossessão necessária: ética, política e reconhecimento em Judith Butler. In: BUTLER, Judith. Relatar a si mesmo. Crítica da violência ética. Tradução de Regina Bettoni. Belo Horizonte: Autêntica Editora, 2015. P. 173-196.

SARAIVA, K. Outros Tempos, Outros Espaços: internet e educação. 2006 Tese (Doutorado em Educação) - Programa de Pós-Graduação em Educação, Faculdade de Educação, Universidade Federal do Rio Grande do Sul, Porto Alegre, 2006.

SEDGWICK, Eve Kosofsky. A Epistemologia do Armário. In: Cadernos Pagu. Tradução de Plinio Dentzien. Campinas: Núcleo de Estudos de Gênero Pagu, 2007. p. 19-54.

\title{
NOTAS
}

\author{
Cleber Sales Pereira \\ Discente de Psicologia \\ Universidade Federal do Delta do Parnaíba (UFDPar). \\ Curso de Psicologia, Parnaíba, Brasil. \\ salllescleber@gmail.com \\ (1) https://orcid.org/0000-0003-4446-2955
}

\section{Guilherme Augusto Souza Prado}

Doutor em Psicologia Clínica e Subjetividade pela Universidade Federal Fluminense (UFF) com estágio de doutoramento na Universidade Complutense de Madrid.

Professor adjunto na Universidade Federal do Delta do Parnaíba (UFDPar).

Curso de Psicologia, Parnaíba, Brasil.

guispra@gmail.com

(1) http://orcid.org/0000-0001-9318-8580 
Endereço de correspondência do principal autor

Rua São Jorge, Bairro Pindorama, n. 230, CEP 64215520, Parnaíba- PI, Brasil.

\section{AGRADECIMENTOS}

Não se aplica.

\section{CONTRIBUIÇÃO DE AUTORIA}

Concepção e elaboração do manuscrito: C. S. Pereira, G. A. S. Prado

Coleta de dados: C. S. Pereira

Análise de dados: $C$. S. Pereira

Discussão dos resultados: C. S. Pereira, G. A. S. Prado

Revisão e aprovação: G. A. S. Prado

\section{CONJUNTO DE DADOS DE PESQUISA}

O conjunto de dados que dá suporte aos resultados deste estudo não está disponível publicamente.

\section{FINANCIAMENTO}

Não se aplica.

\section{CONSENTIMENTO DE USO DE IMAGEM}

Não se aplica

\section{APROVAÇÃO DE COMITÊ DE ÉTICA EM PESQUISA}

Não se aplica.

\section{CONFLITO DE INTERESSES}

Não se aplica

LICENÇA DE USO - uso exclusivo da revista

Os autores cedem à Revista Internacional Interdisciplinar INTERthesis os direitos exclusivos de primeira publicação, com o trabalho simultaneamente licenciado sob a Licença Creative Commons Attribution (CC BY) 4.0 International. Estra licença permite que terceiros remixem, adaptem e criem a partir do trabalho publicado, atribuindo o devido crédito de autoria e publicação inicial neste periódico. Os autores têm autorização para assumir contratos adicionais separadamente, para distribuição não exclusiva da versão do trabalho publicada neste periódico (ex.: publicar em repositório institucional, em site pessoal, publicar uma tradução, ou como capítulo de livro), com reconhecimento de autoria e publicação inicial neste periódico.

PUBLISHER - uso exclusivo da revista

Universidade Federal de Santa Catarina. Programa de Pós-graduação Interdisciplinar em Ciências Humanas. Publicação no Portal de Periódicos UFSC. As ideias expressadas neste artigo são de responsabilidade de seus autores, não representando, necessariamente, a opinião dos editores ou da universidade.

EDITORES - uso exclusivo da revista

Javier Ignacio Vernal, Silmara Cimbalista e Selvino José Assmann (In Memoriam).

EDITOR ASSISTENTE: Eixo temático: (Re)discutindo sexualidade: corpo, prazer e desejo em tempos conservadores

Luiz Barp

HISTÓRICO - uso exclusivo da revista

Recebido em: 30-07-2020 - Aprovado em: 20-05-2021 - Publicado em: 28-05-2021 